\title{
Jamovi: An Easy to Use Statistical Software for the Social Scientists
}

\author{
Murat Doğan Şahin'1 (iD*, Eren Can Aybek² \\ ${ }^{1}$ Department of Educational Measurement and Evaluation, Anadolu University, Eskişehir, Turkey \\ ${ }^{2}$ Department of Educational Measurement and Evaluation, Pamukkale University, Denizli, Turkey
}

\begin{abstract}
ARTICLE HISTORY
Received: 03 August 2019

Revised: 31 October 2019

Accepted: 16 December 2019

KEYWORDS

Jamovi,

$\mathrm{R}$,

Statistical software,

Abstract: This report aims to introduce the fundamental features of the free Jamovi software to academics in the field of educational measurement for use at undergraduate and graduate level research. As such, after introducing the $\mathrm{R}$ based interface and the integrated development environment, the core functions of Jamovi are presented, the installation for GNU7Linux, Windows, and MacOS is explained and screenshots of frequently conducted statistical analyses are provided. Additionally, the module support of Jamovi is presented, along with a use case scenario on developing further functionality for Jamovi using modules. Specifically, conducting metaanalysis and Bayesian statistics using modules in Jamovi are explained through examples.
\end{abstract}

Free software

\section{INTRODUCTION}

One of the most important stages of scientific research, data analysis, was one conducted by hand and then by calculators. Today, various computer software is used to assist this process. The public access provided to data from wide-scale tests such as the Programme for International Student Assessment (PISA) and Trends in International Mathematics and Science Study (TIMMS), along with the rapid increase in the amount of data collected in social sciences have made statistical software an integral part of the quantitative research process.

Muenchen (2019) determined the market shares of statistical software, concluding that IBM's SPSS Statistics program was the most preferred software in academic studies as of the end of 2018. Meanwhile, $R$ has been referenced half as much as IBM's SPSS Statistics program in academic articles. The situation may be attributed to the ease of use of SPSS through its graphical user interface, it being used extensively by academics for many years, and SPSS being the primary software used in statistics training and education. Despite lacking the ease of use of SPSS, as the second most popular software in the field, $\mathrm{R}$ has gained new functionality through packages published by researchers around the world due to its open source nature. $\mathrm{R}$ is a GNU project which is similar to the $\mathrm{S}$ language and environment which was developed at Bell Laboratories (Formerly AT\&T, now Lucent Technologies) by John Chambers and colleagues

CONTACT: Murat Doğan Şahin $\bigotimes$ mdsahin@anadolu.edu.tr Eskişehir, Turkey 
(R Core Team, 2019a). GNU is an acronym for GNU is Not Unix, and is a free operating system developed by Richard Stallman in 1983 (GNU, 2019). While R is free software developed based on this operating system, today it is capable of running on common operating systems such as GNU/Linux, Microsoft Windows, and Mac OS X. Developed on the free and open software philosophy of GNU, anyone may download and use R, study its code, modify it and distribute their modifications (R Core Team, 2019a). Screenshots of IBM SPSS Statistics v.20 and R may be compared in Figure 1.

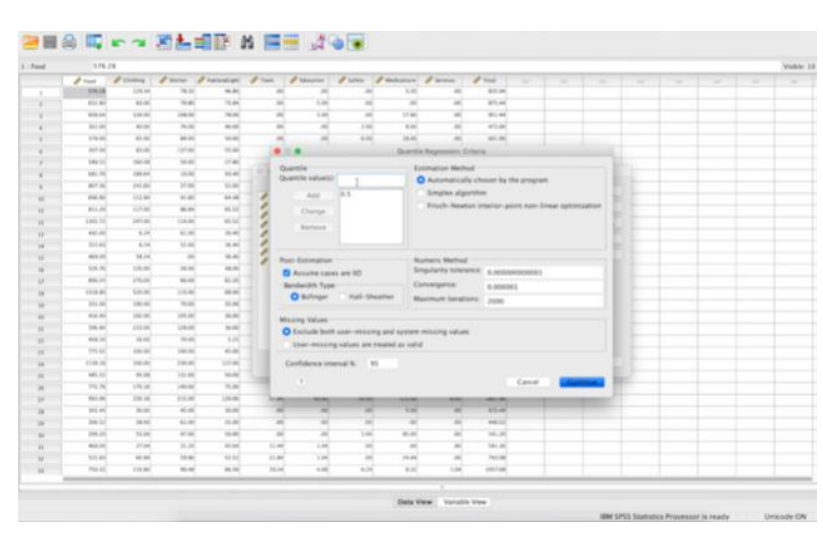

(a) IBM SPSS Statistics v26 for OS X

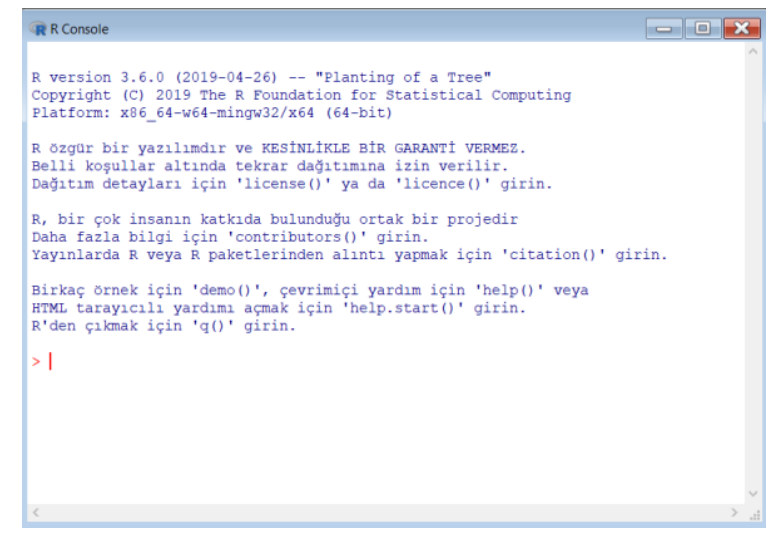

(b) R v.3.6.0 (Console) for Windows

Figure 1. Screenshots for IBM SPSS Statistics and $\mathrm{R}$

(a) Source URL: https://www.ibm.com/downloads/cas/RJBNRBVB

As can be seen in Figure 1, while R only provides the user with a console screen, IBM statistics allows users to conduct any analysis they want (albeit any analysis the developers allow) with a few mouse clicks. While $\mathrm{R}$ may only have a console, it can download a package developed by a researcher from another part of the world with a simple install.packages() function and conduct any analysis. The analyses users may conduct in R are 'limited' to the more than 15000 packages developed for R (R Core Team, 2019b). Additionally, users can develop their own packages and offer them for use by other researchers around the world. In this regard, while SPSS is a user-friendly program with limited functionality, $R$ appears limitless but cumbersome in comparison. Considering researchers, especially those in social sciences, may not be skilled at coding, it's easy to understand the reasoning behind the proliferation of IBM SPSS Statistics.

\subsection{Statistical Software and Resources}

The prevalent use of SPSS by academics allows them to transfer this use to future generations, namely students. 11 of the results on the first page of an Amazon.com search for books on statistics for social science are for IBM SPSS Statistics, while only two are results pertaining to $\mathrm{R}$ (Amazon, 2019). This situation is indicative of the prevalence of SPSS in statistics education. Teaching the use of proprietary software to undergraduate and graduate students encourages future professionals and researchers to use this proprietary software.

\subsection{R and Its Graphical User Interfaces / Integrated Development Environments}

As can be seen in Figure 1, the interface of R fundamentally consists merely of a screen terminal. While functions such as package loading, package retrieval, and statistical analysis is possible through the terminal, it is clearly not user-friendly. Therefore, various interfaces and integrated development environments aiming to ease the use of R were developed. RKWard, RStudio, JASP, and Jamovi are a few of them. 
RKWard is a comprehensive interface developed for R (RKWard, 2019). It provides access to the $\mathrm{R}$ terminal and allows for point-and-click analyses through its interface. The Spreadsheet function allows variable definition and data entry, correlation, regression and average comparison along with item response theory analyses. RKWard is free software and a screenshot is presented in Figure 2.

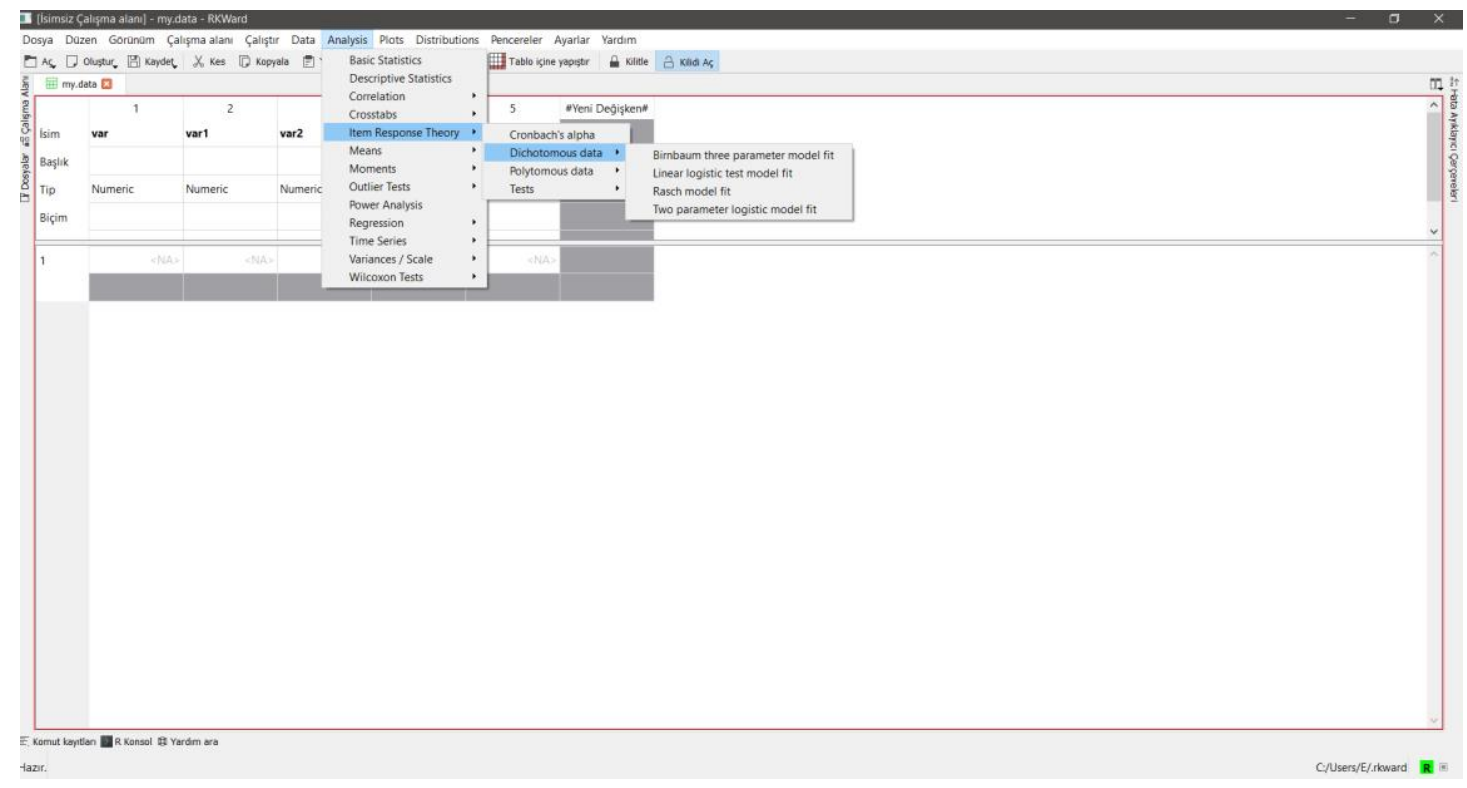

Figure 2. Screenshot for RKWard 0.7.0b

RStudio is an Integrated Development Environment (IDE) that has become synonymous with $\mathrm{R}$ (RStudio, 2019). The greatest advantage of RStudio is the easy access it provides to the objects being studied and the graphs created in R. Additionally, it simplifies working with $\mathrm{R}$ scripts. Furthermore, RStudio has simplified creating project folders and version tracking through git while providing the possibility of writing cleaner $\mathrm{R}$ code through plugins. The basic packages developed for data science in $\mathrm{R}$ are gathered under tidyverse in RStudio. The Shiny package, which allows the creation of a web interface for $\mathrm{R}$ code, is also developed by RStudio. A screenshot for RStudio is presented in Figure 3.

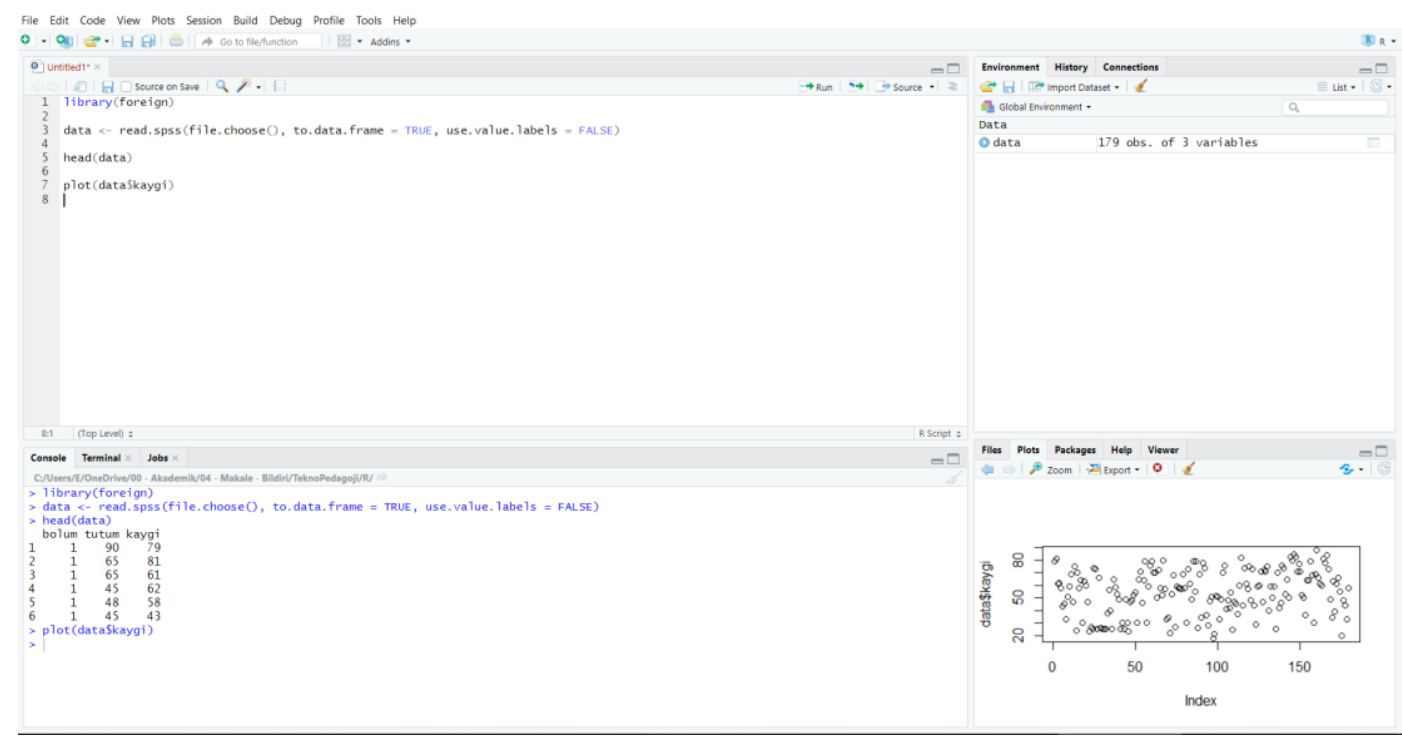

Figure 3. Screenshot for RStudio 
JASP is a simple interface software developed on R (JASP Team, 2019). JASP stands out with its support for Bayesian methods, allowing the user to conduct Bayesian t-tests and Bayesian ANOVA with a few clicks. Additionally, JASP is capable of conducting tests using a frequentist approach and has gained powerful functions such as network analysis, machine learning algorithms, meta-analysis, and structural equation modeling through current modules. JASP supports many data formats such as cxv, xls, and sav, and allows for data analysis but does not allow for data manipulation. JASP runs on GNU/Linux, Windows, and MacOS, and can also be used online through Rollapp. A screenshot of JASP is provided in Figure 4.

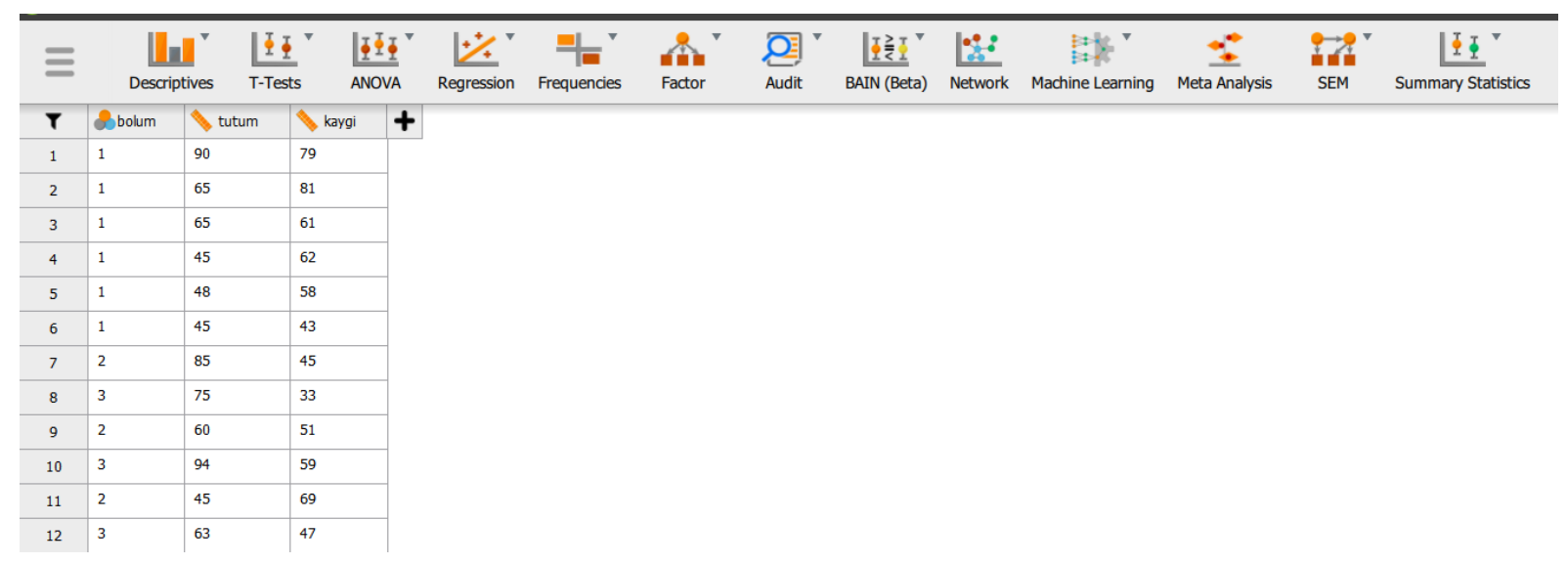

Figure 4. Screenshot for JASP

Another free software based on R, and the locus of this article, is Jamovi. Detailed information on Jamovi is provided in the sections below.

\section{JAMOVI}

\subsection{Developers}

Jamovi is being developed by a team who branched off from JASP developers and started running their own project (The Jamovi Project, 2019a). Jonathan Love, Damian Dropmann and Ravi Selker are members of this team. In their own words; "we found that our goals and ambitions consistently went beyond their scope, and decided the best way to move forward was to found a new project: the jamovi project" (The jamovi project, 2019b).

Possibly the most significant point emphasized by the developers is the community-driven aspect. This means that users in the community may add new features to Jamovi by adding modules. Thus, Jamovi does not remain limited to the initiatives taken by the developer team. In this regard, Jamovi adopts a policy highly suited to the free software philosophy.

\subsection{Features}

Jamovi provides core functions such as data entry and manipulation, rule based data filtering and variable transformation, and computing with variables. Compatible with popular data file formats such as csv, RData, dta, and sav, Jamovi is capable of conducting many single and multiple variable analyses. Among these analyses are descriptive statistics, t-tests, ANOVA, ANCOVA, MANCOVA, linear and logistic regression, exploratory and confirmatory factor analysis, and nonparametric tests.

Additionally, the module support of Jamovi allows developers to add new functionality if the so please. For example, Walrus for robust statistics and MAJOR for meta-analysis are modules developed and added to the Jamovi library. In this regard, Jamovi presents itself as a sufficient, 
useful, and free tool for academic research in social sciences in addition to undergraduate and graduate level statistics courses.

\subsection{Installation}

Once the download link on the Jamovi web site is clicked, links for two different versions of Jamovi are presented. One of them is solid, while the other is the current release. While the solid version is more stable, the current version includes the latest features of Jamovi. While both versions are available for Windows and macOS, only the current version is provided for GNU/Linux and ChromeOS. All Jamovi releases are designed for 64-bit operating systems. The installation steps for Jamovi on GNU/Linux, Windows, and macOS are provided below. As the steps taken are very similar to GNU/Linux, the instructions for ChromeOS are not included in this report.

\subsubsection{Installing on GNU/Linux}

Jamovi for GNU/Linux distributions may be installed through Flatpak. Flatpak is a tool for compiling and distributing desktop applications in GNU/Linux distributions. Multiple programs may be installed with a single command through Flatpak. For installation, Flatpak must be installed on GNU/Linux. Flatpak may be installed by following the instructions at https://flatpak.org/setup/. There are instructions for multiple GNU/Linux distributions at this address. Within this article, installation was conducted on Pop_OS! 19.10, a GNU/Linux distribution based on Ubuntu.

The following terminal command is entered for the installation of Flatpak:

sudo apt install flatpak

Following this command, the superuser (administrator) password will be requested for the sudo operation. Once the password is entered, installation begins. The Flatpak installation is confirmed through the dialog by pressing $\mathrm{Y}$ and the installation of Flatpak is completed. To install Flatpak programs, the Flatpak repositories need to be added. This is achieved with the following terminal command:

flatpak remote-add --if-not-exists flathub

https://flathub.org/repo/flathub.flatpakrepo

Once the computer is restarted after this, the Terminal is opened once again and the following command is entered:

flatpak install flathub org.jamovi.jamovi

The dialogs are confirmed by pressing $\mathrm{Y}$, and once the necessary files for Jamovi are downloaded, it is installed on the computer.

\subsubsection{Installing on Windows}

Once the desired version (solid or current) is downloaded, double clicking on the installation file initiates the installation. Once the Install button is clicked, Jamovi is installed and completed by clicking the Finish button. The three screens that appear during installation are presented in Figure 5. 


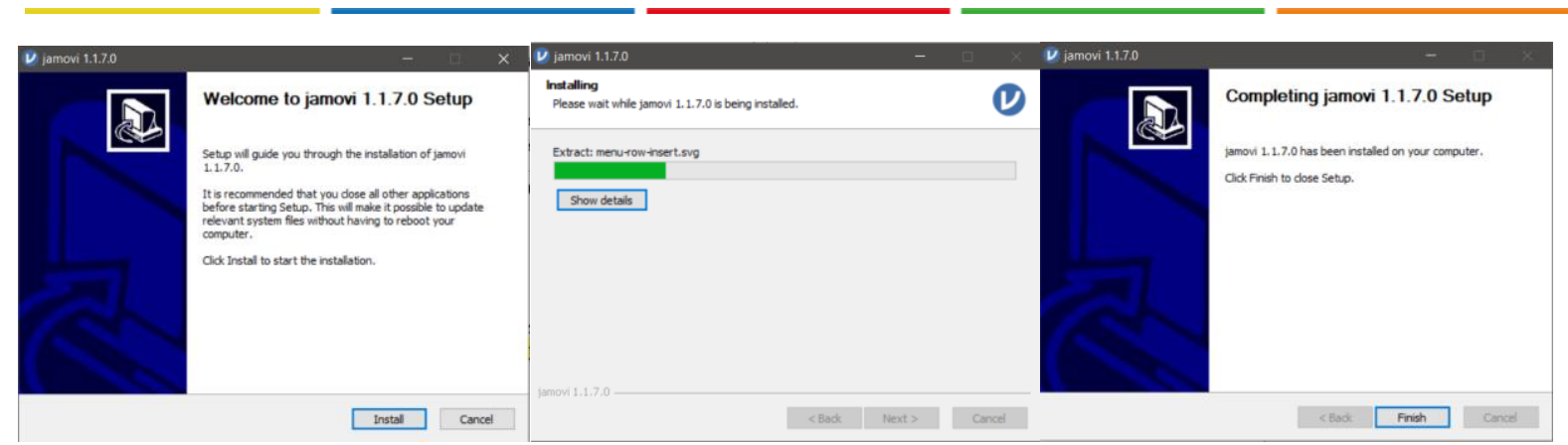

Figure 5. Jamovi Windows Installation Screens

\subsubsection{Installing on macOS}

Similar to the Windows installation, the desired version is downloaded. Double clicking on the Jamovi image within the downloaded file opens the program in a new window. This process is presented in Figure 6.

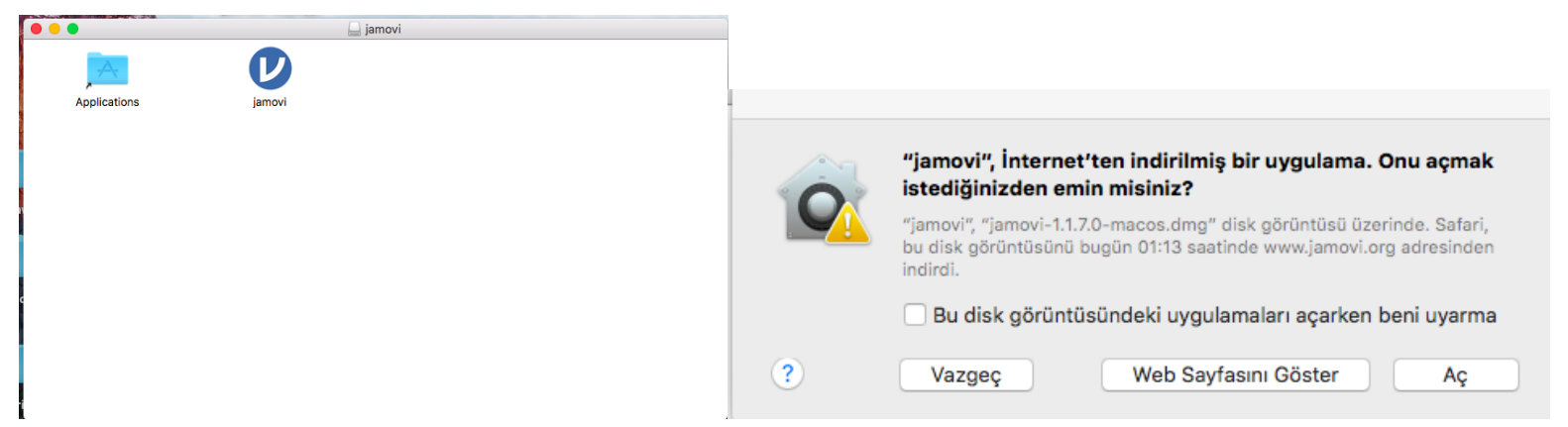

Figure 5. Jamovi macOS Installation Screens

\subsection{First Look}

Following installation, Jamovi can be run by double clicking the shortcut icon. Additionally, it can be run from the terminal in GNU/Linux with the flatpak run org.jamovi.jamovi command. The first screen to be encountered in Jamovi is presented in Figure 7.

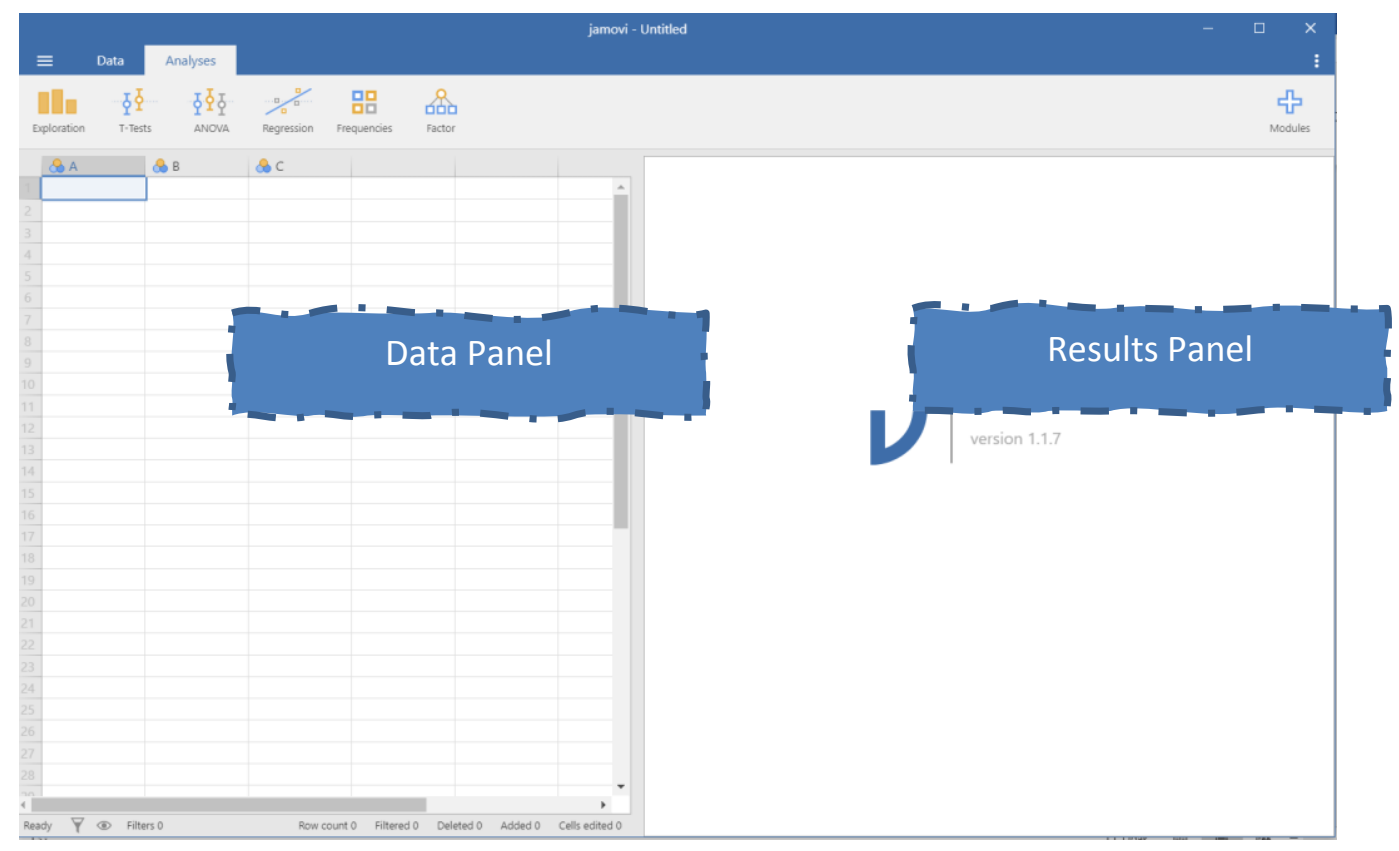

Figure 7. Jamovi Initial Screenshot 
Jamovi has Data and Analyses tabs at the top left corner. The Data tab provides processes regarding variables, while the Analyses tab is used to execute data analysis processes. The window is divided basically into two panels. The data is presented in the left panel, while the analysis results are presented in the right. When data analysis is to be conducted, a menu regarding the analysis is presented instead of the data panel. The options in the data tab are presented in Figure 8.

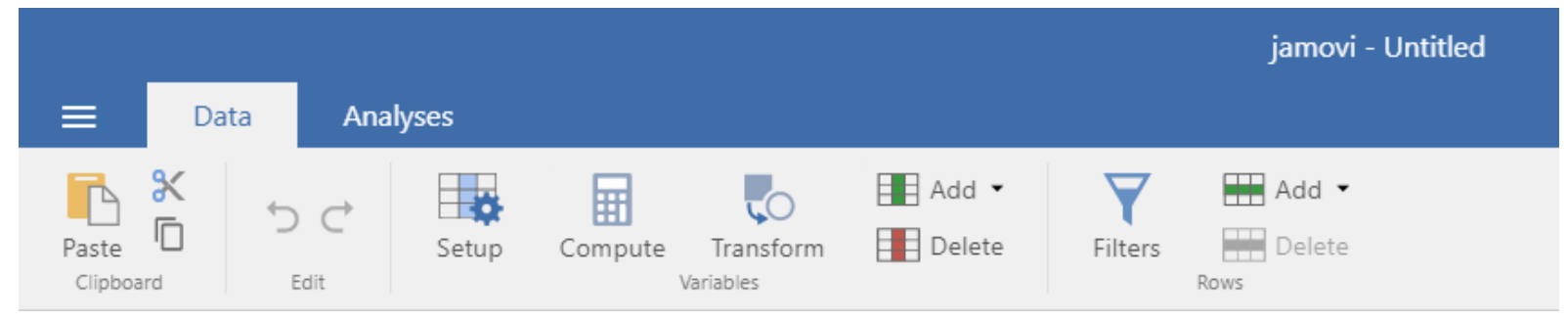

Figure 8. Jamovi Data Tab

Within the data tab, data pasting/copying, variable definition, calculation and transformation, variable addition and removal, and rule-based filtering can be conducted. A detailed image of the menus in the Analyses tab are presented in Figure 9.

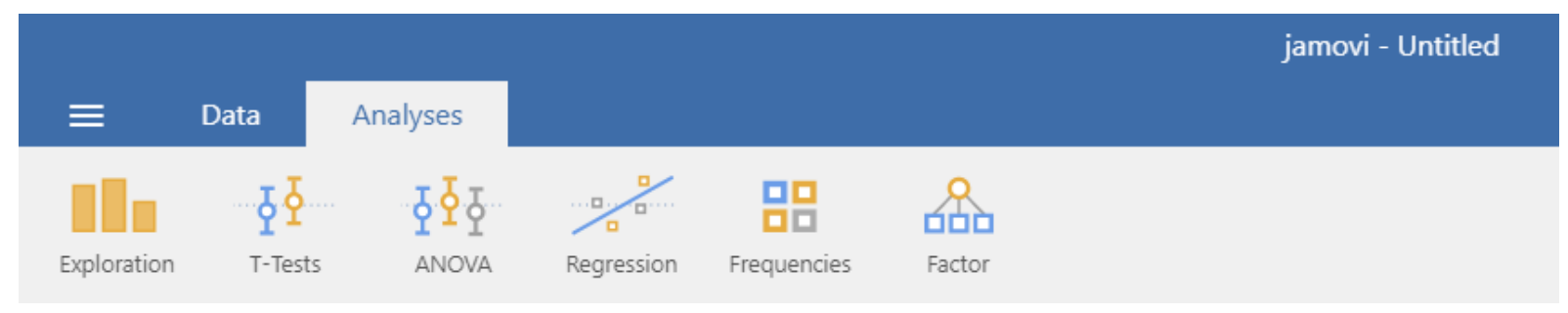

Figure 9. Jamovi Analyses Tab

In this tab, the default analyses available upon the initial installation of Jamovi are listed. New analyses added through modules are added to this section. By default, Jamovi is capable of conducting descriptive statistics, independent samples t-test, paired samples t-test, one sample t-test, Mann-Whitney U test, Wilcoxon signed rank test, one way ANOVA, repeated measures ANOVA, ANCOVA, MANCOVA, Kruskal-Wallis H test, Friendman test, Correlation, Linear regression, Logistic regression, $\chi^{2}$ Goodness of fit, $\chi^{2}$ test for association, McNemar test, LogLinear regression, reliability analysis, Principal Component Analysis, Exploratory Factor Analysis and Confirmatory Factor Analysis. Additionally, the assumptions of these tests may be tested using Jamovi.

\subsection{Data Setup}

Prior to data entry, the data must be defined. To do this, the Setup button under the Data tab is clicked and the screen presented in Figure 10 appears. 


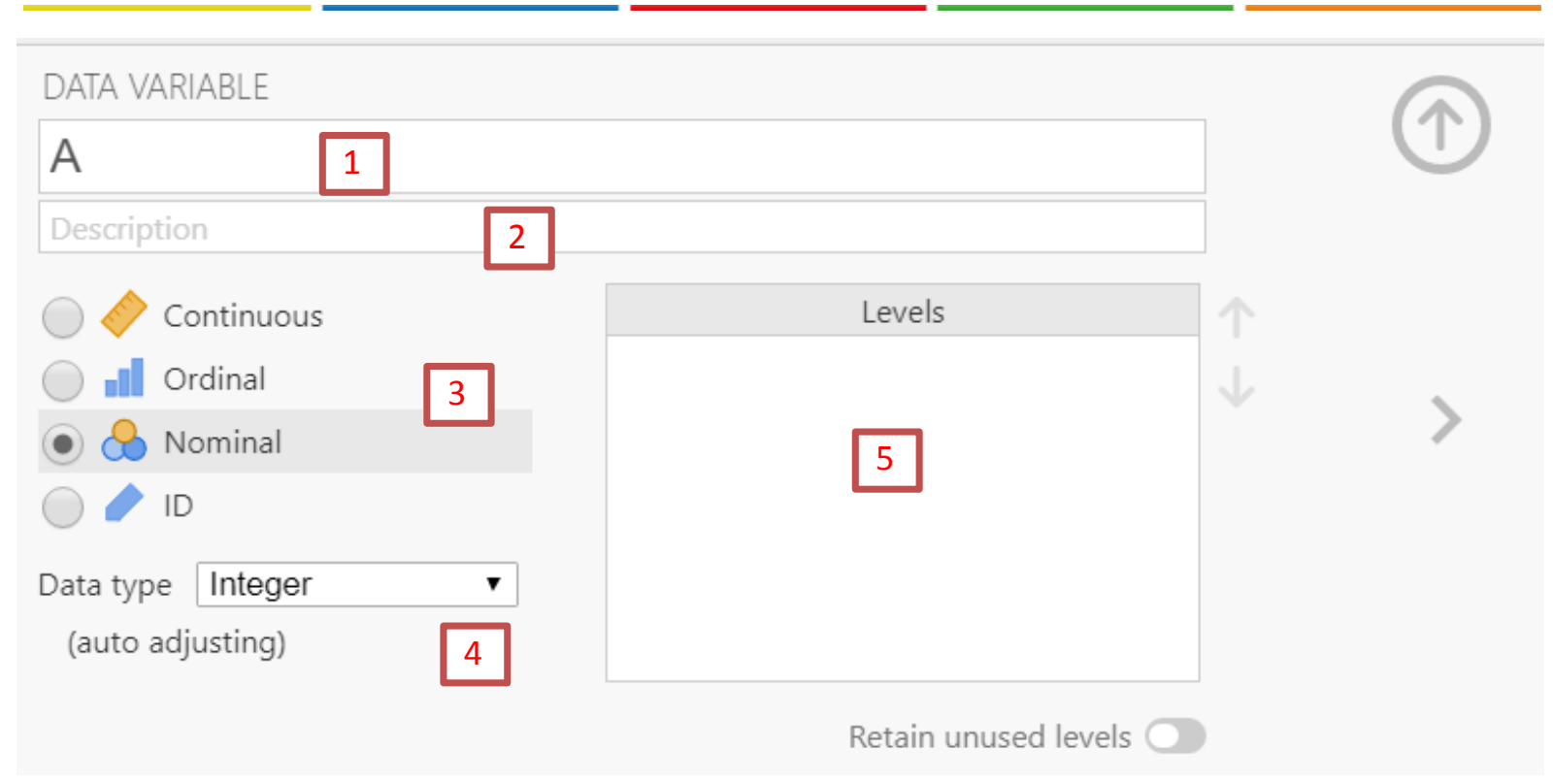

Figure 10. Data Setup Menu

In this screen, the name of the variable is defined in the section marked 1 , while an explanation regarding this variable may be entered in the field marked 2 if desired. The level of measurement for the variable may be defined in the field marked 3. What is interesting is that in addition to the continuous, ordinal, and nominal options, an option labelled ID is presented. This feature is useful for when participants of a study are assigned ID numbers and greatly eases data entry. The nature of the data to be entered, whether it be integer, decimal, or text, is specified through field 4 . The field marked 5 is used to define the levels of nominal variables.

\subsection{Statistical Analyses}

The statistical analyses that Jamovi is capable of executing by default were presented in section 2.4 First Look. The focus of this section is on how statistical analyses are conducted in Jamovi in detail, along with examples for descriptive statistics, independent samples t-tests, dependent samples t-tests, one-way ANOVA, correlation, linear regression, and exploratory and confirmatory factor analysis.

\subsubsection{Descriptive Statistics}

To conduct descriptive statistics in Jamovi, the Descriptives option is selected from the Exploration menu. The screen presented in Figure 11 appears following these actions. 


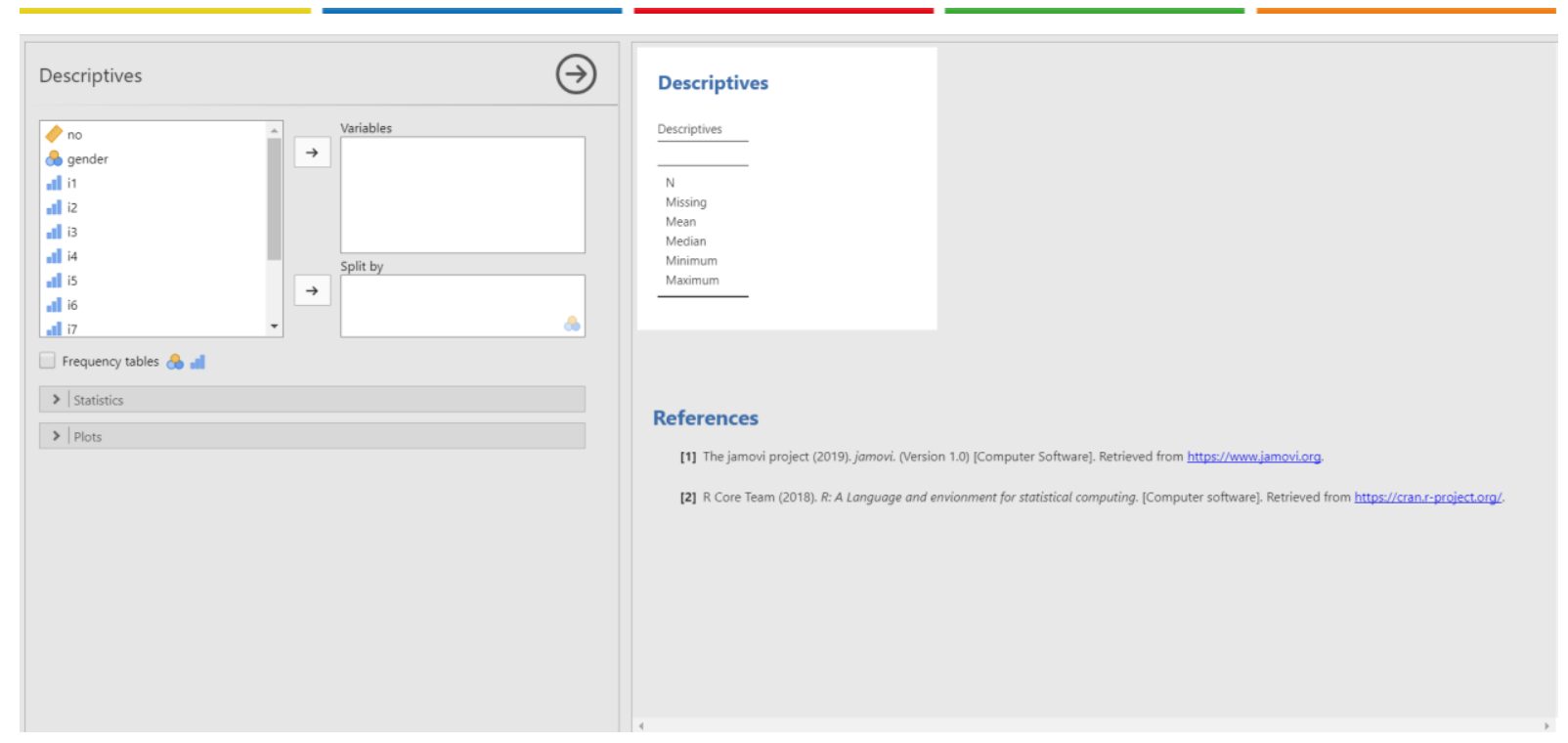

Figure 11. Descriptive Statistics Menu

As can be seen, the variables and analysis options are on the left, while the analysis results are on the right. Additionally, a reference section is presented for researchers to refer to this program in the studies in the APA style.

On this screen, once the Statistics menu is opened; $N$, missing value, Quartiles, standard deviation, variance, range, minimum, maximum, standard error, mean, median, mode, sum, skewness, kurtosis statistics along with the Shapiro-Wilk normality test are presented. Under the Plots menu, the options presented are histogram, density, Q-Q, box-plot, violin and bar plots.

As an example, if one were to require the descriptive statistics of total score based on sex, the sum variable is moved to Variables, while the gender variable is moved to the split by section. This is then followed by selecting the histogram graph and the Shapiro-Wilk test. The results of this analysis are presented in figure 12.

\begin{tabular}{|c|c|c|}
\hline \multicolumn{3}{|l|}{ Descriptives } \\
\hline & gender & sum \\
\hline \multirow[t]{2}{*}{$N$} & Male & 27 \\
\hline & Female & 23 \\
\hline \multirow[t]{2}{*}{ Missing } & Male & 0 \\
\hline & Female & 0 \\
\hline \multirow[t]{2}{*}{ Mean } & Male & 25.3 \\
\hline & Female & 25.3 \\
\hline \multirow[t]{2}{*}{ Median } & Male & 26.0 \\
\hline & Female & 25.0 \\
\hline \multirow[t]{2}{*}{ Minimum } & Male & 14.0 \\
\hline & Female & 20.0 \\
\hline \multirow[t]{2}{*}{ Maximum } & Male & 34.0 \\
\hline & Female & 34.0 \\
\hline \multirow[t]{2}{*}{ Shapiro-Wilk p } & Male & 0.166 \\
\hline & Female & 0.342 \\
\hline
\end{tabular}

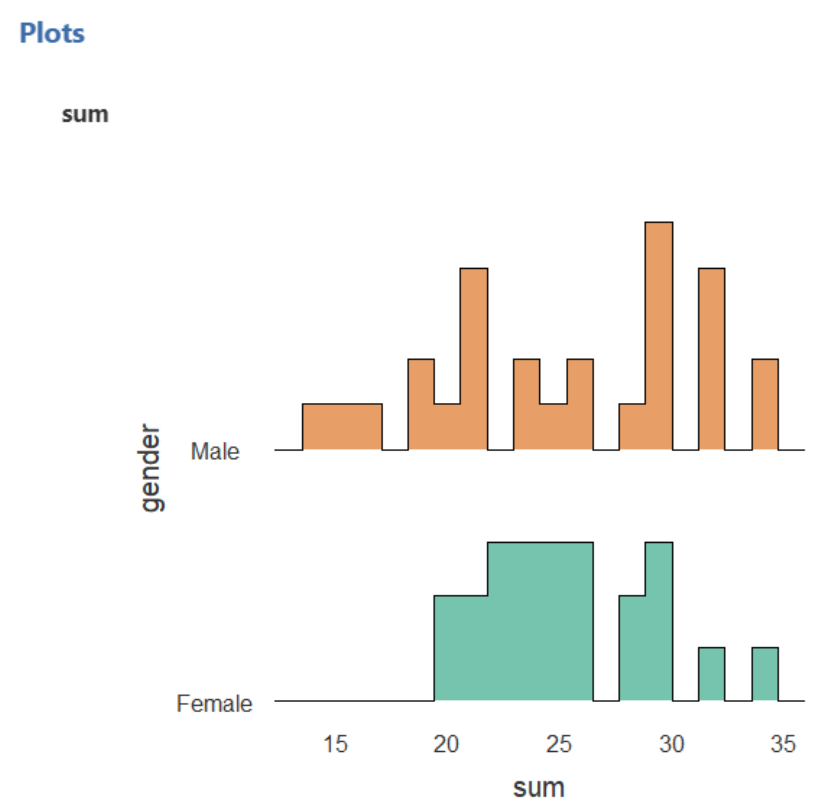

Figure 12. Descriptive Statistics

As can be seen from the figure, the descriptive statistics are calculated and presented separately based on gender. 


\subsubsection{Independent Samples $t$ Test}

Indepentent samples t-tests, which are conducted to compare the arithmetic means of two indepentent samples (Field, 2013) may be executed by clicking on the Independent Samples T Test option under the T-Tests menu. This menu is presented in Figure 13.

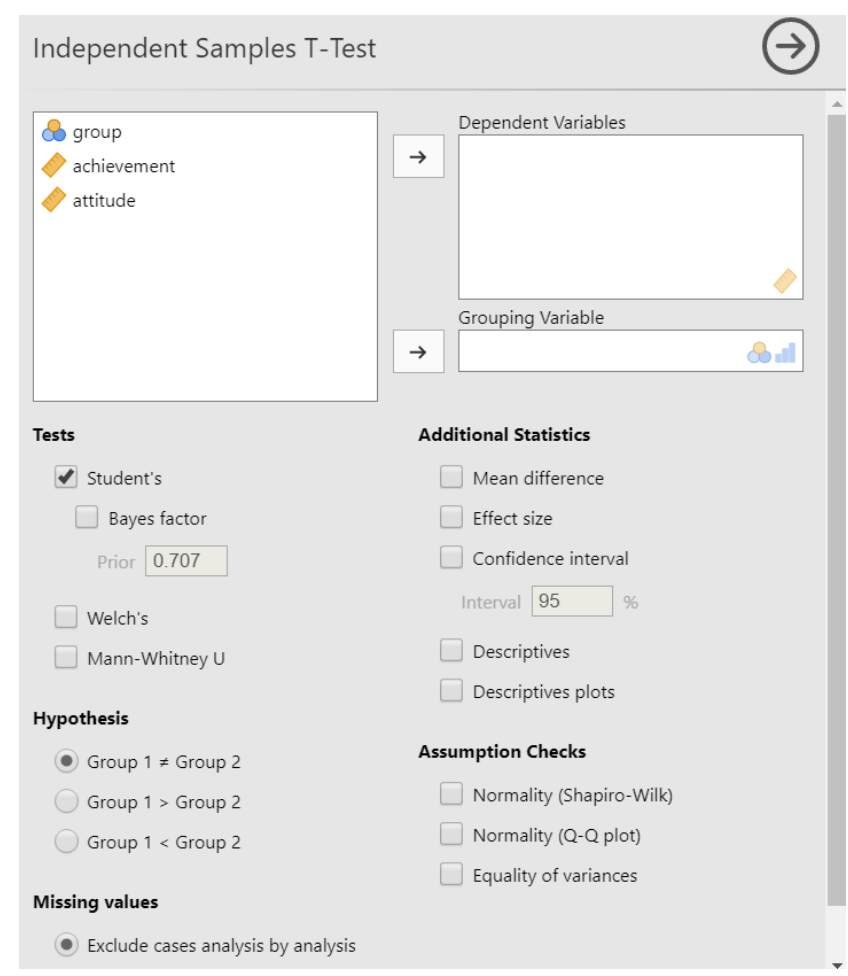

Figure 13. Independent Samples t Test Menu

The dependent variable is assigned to the dependent variables field, while the independent variable is assigned to the grouping variable field. The options for the test include a Student ttest for equal variance, a Welch test for unequal variance, and a Mann-Whitney U test as a nonparametric test. Analysis results may be obtained based on two-way or one-way hypotheses, and tests such as the effect size, descriptive statistics, normality, and variance equality may all be requested under a single menu.

For examples, to determine if there is any significant difference between the academic achievement of students in groups $\mathrm{A}$ and $\mathrm{B}$, the findings of the independent samples t-test results are presented in Figure 14. 
Şahin \& Aybek

\begin{tabular}{llcccccc}
\multicolumn{1}{l}{ Independent Samples T-Test } & \multicolumn{1}{l}{} \\
\hline & statistic & df & $\mathrm{p}$ & Mean difference & SE difference & Cohen's d \\
\hline \multirow{2}{*}{ achievement } & Student's t & $0.450^{\circ}$ & 98.0 & 0.654 & 0.920 & 2.04 & 0.0900 \\
& Welch's t & 0.450 & 93.0 & 0.654 & 0.920 & 2.04 & 0.0900 \\
\hline
\end{tabular}

- Levene's test is significant $(p<.05)$, suggesting a violation of the assumption of equal variances

Assumptions

Test of Normality (Shapiro-Wilk)

\begin{tabular}{ccc}
\hline & $W$ & $p$ \\
\hline achievement & 0.988 & 0.542 \\
\hline
\end{tabular}

Note. A low p-value suggests a

violation of the assumption of

normality

Test of Equality of Variances (Levene's)

\begin{tabular}{ccccc}
\hline & $\mathrm{F}$ & $\mathrm{df}$ & $\mathrm{df} 2$ & $\mathrm{p}$ \\
\hline achievement & 4.52 & 1 & 98 & 0.036
\end{tabular}

Note. A low p-value suggests a violation of the assumption of equal variances

[3]

\begin{tabular}{llcrrrr}
\multicolumn{1}{l}{ Group Descriptives } & \multicolumn{6}{l}{} \\
\hline & Group & N & Mean & Median & SD & SE \\
\hline achievement & A & 50 & 68.9 & 68.0 & 8.96 & 1.27 \\
& B & 50 & 68.0 & 65.7 & 11.3 & 1.60 \\
\hline
\end{tabular}

Figure 14. Independent Samples t-Test Output

As can be seen, the assumption test, test results, and effect size for the independent samples t-test may be requested from the same menu and the outputs may be portrayed in the same section.

\subsubsection{Paired Samples $t$ Test}

The comparison of the means of two dependent measurements are conducted using a paired samples t-test (Navarro \& Foxcroft, 2019). To this end, under the T-Tests button in Jomavi, the Paired Samples T-Test path is selected. Jamovi's menu for paired samples t-tests is shown in Figure 15. 


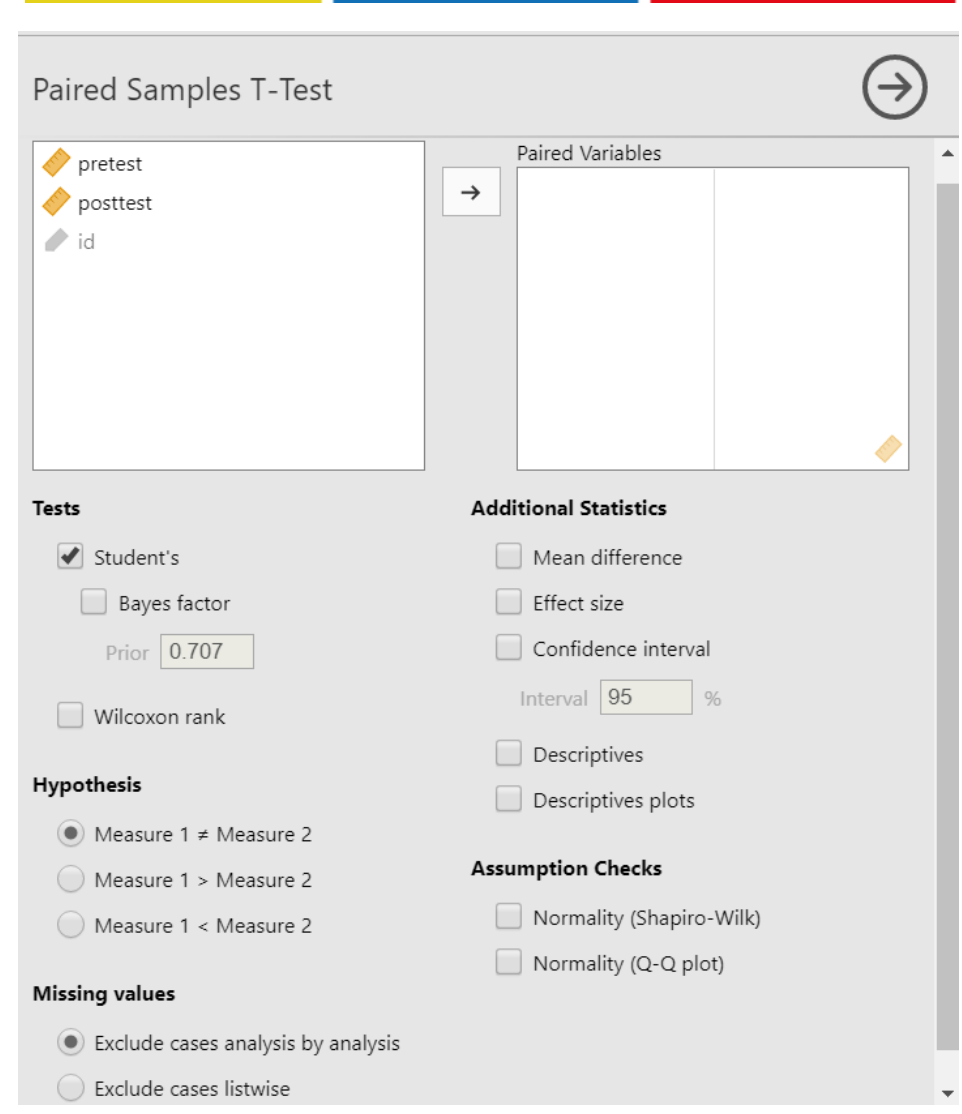

Figure 15. Paired Samples t Test Menu

In this menu, the selection between paired samples t-test and the Wilcoxon signed-rank test as a nonparametric test may be done. Additionally, the assumptions to be tested may be determined as either one-way or two-way. Information regarding assumptions such as effect size, descriptive statistics and normality tests may also be requested. The results of a simple paired samples t-test with effect size and normality tests is presented in Figure 16.

\section{Paired Samples T-Test}

\begin{tabular}{lrrrrrr}
\hline \multicolumn{2}{l}{ Paired Samples T-Test } \\
\hline \multicolumn{1}{l}{ statistic } & df & p & Cohen's d \\
\hline pretest & posttest & Student's t & 36.6 & 39.0 & $<.001$ & 5.79 \\
\hline
\end{tabular}

\begin{tabular}{|c|c|c|c|c|}
\hline & & & statistic & $\mathrm{p}$ \\
\hline \multirow[t]{3}{*}{ pretest } & posttest & Shapiro-Wilk & 0.960 & 0.169 \\
\hline & & Kolmogorov-Smirnov & 0.0920 & 0.856 \\
\hline & & Anderson-Darling & 0.513 & 0.183 \\
\hline
\end{tabular}

\begin{tabular}{lcrrrl}
\hline Descriptives & \multicolumn{1}{l}{} & & & \\
\hline pretest & $\mathrm{N}$ & Mean & Median & SD & SE \\
posttest & 40 & 143.0 & 140.3 & 9.16 & 1.448 \\
& 40 & 76.6 & 77.1 & 4.78 & 0.755 \\
\hline
\end{tabular}

Figure 16. Paired Samples t-test Output

As can be seen from the output, the assumption tests and paired samples t-test results are presented in the same section. 


\subsubsection{One Way ANOVA}

When comparing the means of more than two groups, one-way ANOVA is used (Kline, 2009). In Jamovi, this is done by selecting the One Way ANOVA path under the ANOVA menu and results in a menu such as the one presented in Figure 17.

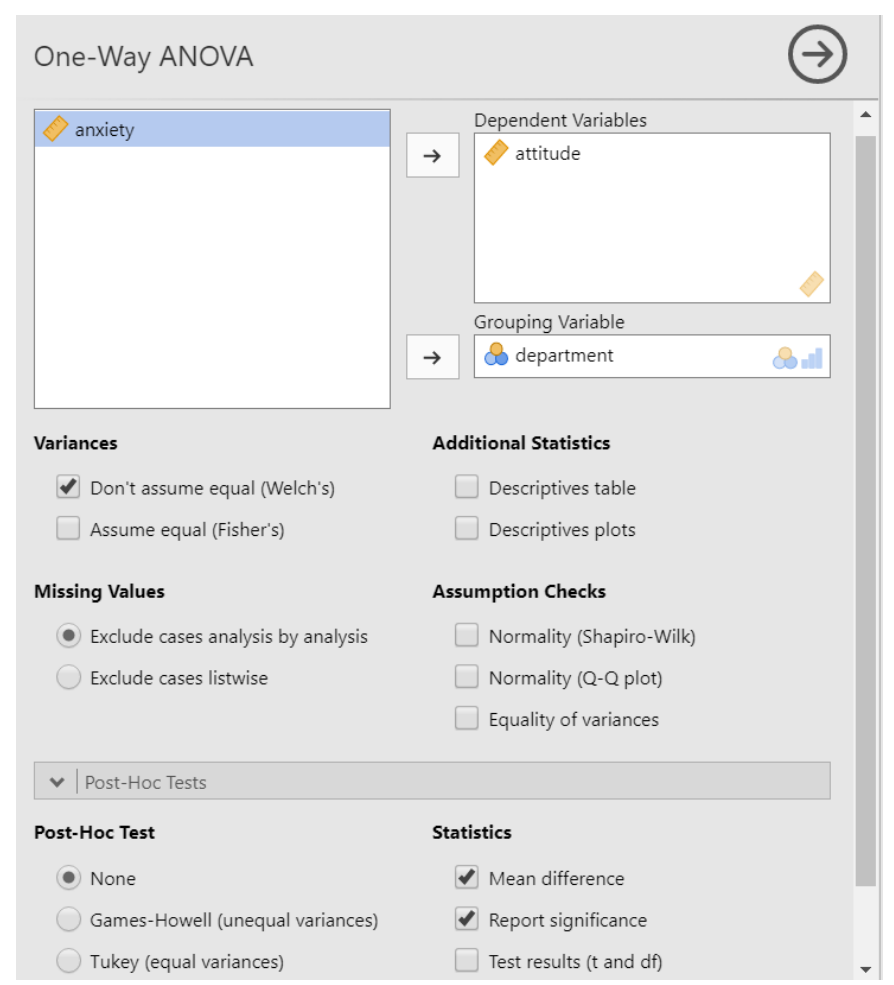

Figure 17. One Way ANOVA Menu

Descriptive statistics, assumption tests, and post-hoc tests are accessible through the One Way ANOVA menu in Jamovi. However, as may be noticed, post-hoc tests such as effect size and Bonferroni are not present in this section. Options for these exist under the ANOVA route of the ANOVA menu in Jamovi. This menu tree is presented in Figure 18.

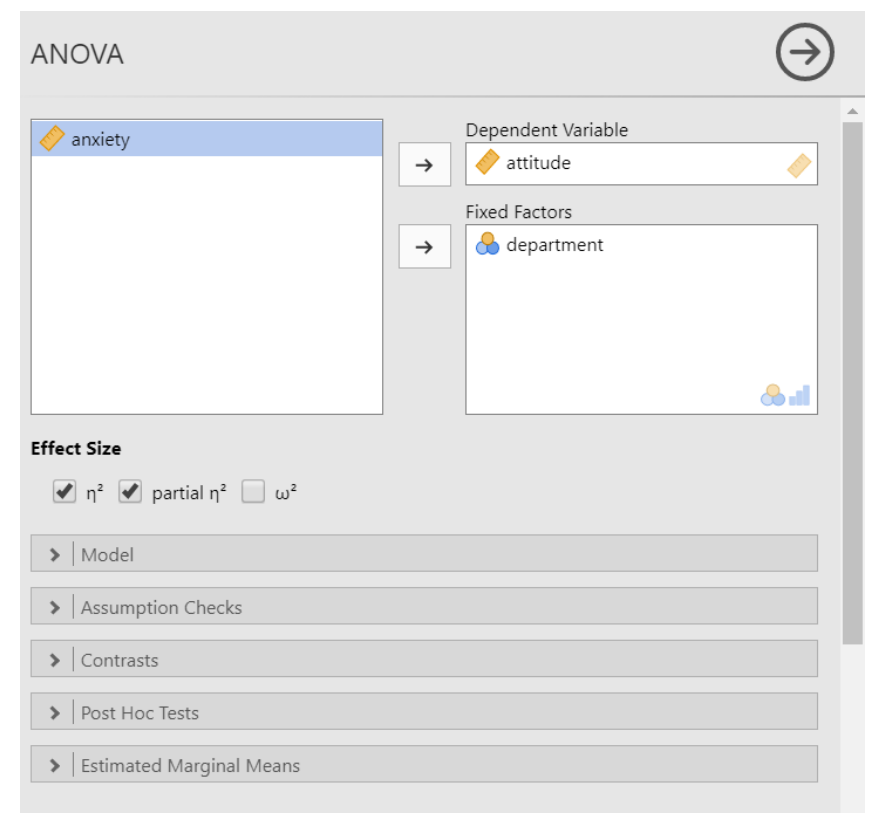

Figure 18. ANOVA Menu 
The results of the analysis conducted using the options under the ANOVA menu are presented in Figure 19. During these tests, the $\eta^{2}$ and partial $\eta^{2}$ effect size calculations were also selected, while the Bonferroni post-hoc test was selected to determine variance homogenity and normality.

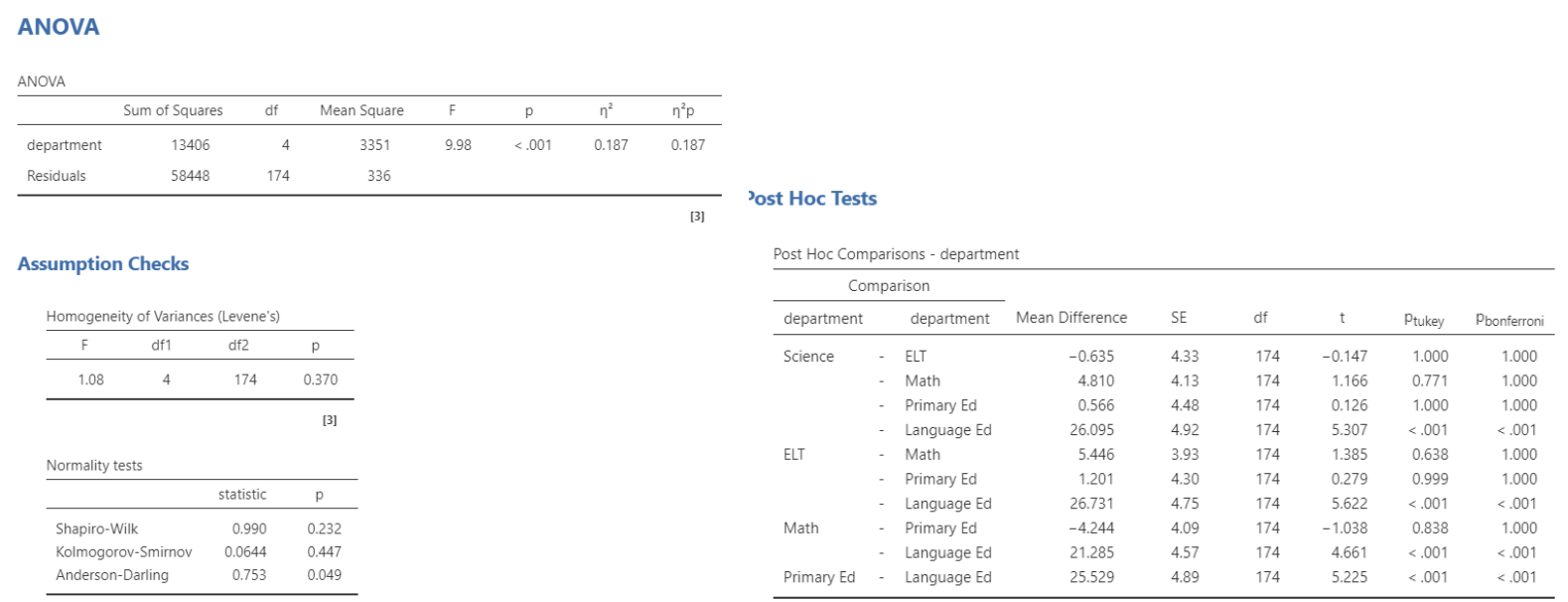

Figure 19. ANOVA Output

As can be seen, the ANOVA results, effect sizes, assumption tests and post-hoc test results are presented in the same section.

\subsubsection{Correlation}

When the correlation coefficient is to be calculated to provide information regarding the direction and size of a relationship between two variables (Warner, 2008), the Regression menu in Jamovi is chosen and the Correlation Matrix is selected. This is followed by a menu presented to users as portrayed in Figure 20.

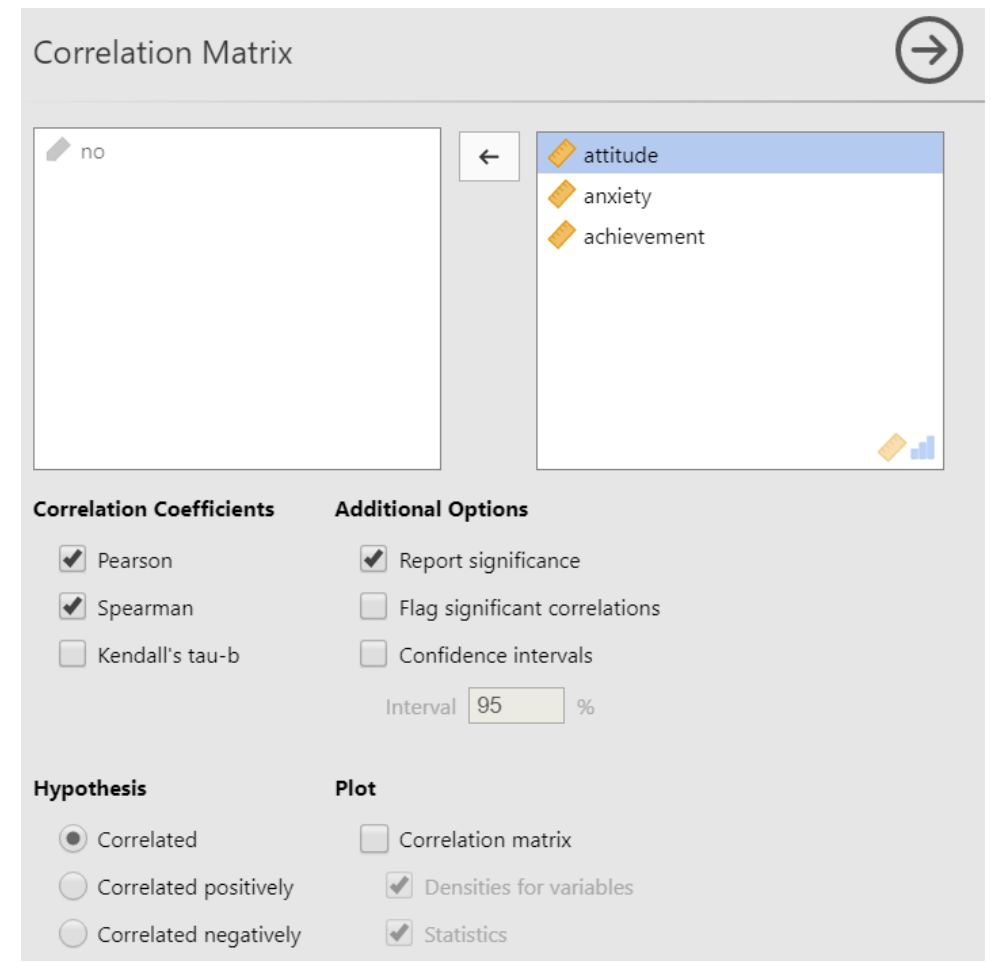

Figure 20. Correlation Menu 
Using this menu, the variables for which a correlation coefficient is to be calculated are selected, and either one, several, or all of the options for Pearson product-moment correlation coefficient, Spearman rank correlation coefficient, or Kendall's tau-b coefficient are selected. The researcher selects the appropriate options of meaningful coefficients, confidence intervals, graphs for the correlation matrix, and the one-way or two-way nature of the hypotheses being tested. An example for the correlation test output is presented in Figure 21.

\section{Correlation Matrix}

\begin{tabular}{llrrr}
\hline \multicolumn{1}{l}{ Correlation Matrix } & & & \\
\hline attitude & & attitude & anxiety & achievement \\
& Pearson's r & - & & \\
& p-value & - & & \\
& Spearman's rho & - & & \\
& p-value & - & & \\
anxiety & Pearson's r & -0.423 & - & \\
& p-value & 0.007 & - & \\
& Spearman's rho & -0.749 & - & \\
& p-value & $<.001$ & - & - \\
achievement & Pearson's r & 0.102 & -0.580 & - \\
& p-value & 0.532 & $<.001$ & - \\
& Spearman's rho & 0.849 & -0.643 & - \\
& p-value & $<.001$ & $<.001$ & - \\
\hline
\end{tabular}

Figure 21. Correlation Output

As shown, a correlation matrix was created from the correlation coefficients between the three variables. Additionally, two types of correlation coefficients were reported with their $p$ values as both Pearson and Spearman were selected.

\subsubsection{Linear Regression}

When one or more predictor variable and one dependent variable is to be estimated, linear regression is utilized (Navarro \& Foxcroft, 2019). To execute linear regression in Jamovi, Linear Regression is selected under the Regression menu as shown in Figure 22.

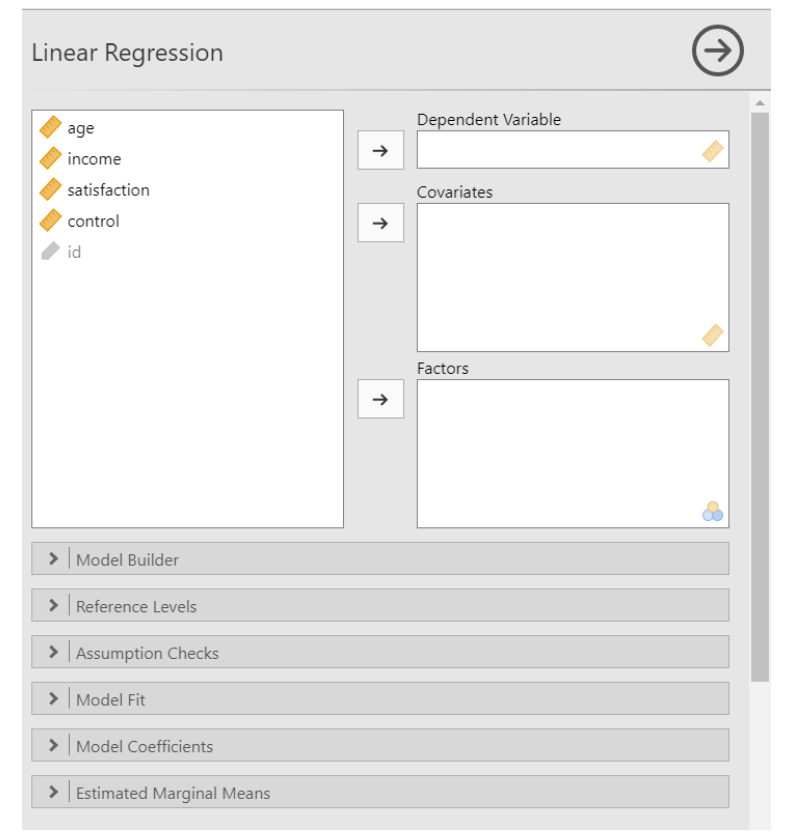

Figure 22. Regression Menu 
In this menu, predictor and dependent variables may be defined, and from the assumption control section autocorrelation tests, collinearity statistics, normality tests, and residual plots may be requested. In addition to the $\mathrm{R}, \mathrm{R}^{2}$, and adjusted $\mathrm{R}^{2}$ values to determine the fit of the regression model, RMSE, F test, AIC and BIC values may also be calculated. Furthermore, standardized coefficients may be retrieved from the Model Coefficients section. The output of a simple multiple regression analysis is provided in Figure 23.

Linear Regression

\begin{tabular}{lcccccc}
\multicolumn{2}{l}{ Model Fit Measures } \\
\hline Model & $R$ & $R^{2}$ & Adjusted $R^{2}$ & AIC & BIC & RMSE \\
\hline 1 & 0.839 & 0.704 & 0.682 & 128 & 134 & 1.79 \\
\hline
\end{tabular}

\begin{tabular}{lrrrrr}
\multicolumn{6}{l}{ Model Coefficients - satisfaction } \\
\hline Predictor & Estimate & SE & \multicolumn{1}{c}{$\mathrm{t}$} & $\mathrm{p}$ & Stand. Estimate \\
\hline Intercept & 15.352 & 3.3394 & 4.60 & $<.001$ & \\
income & 0.525 & 0.1636 & 3.21 & 0.003 & 0.387 \\
control & -0.438 & 0.0919 & -4.77 & $<.001$ & -0.576 \\
\hline
\end{tabular}

Assumption Checks

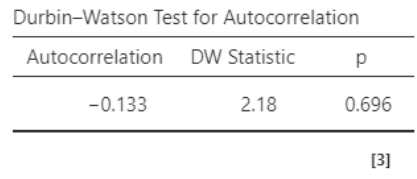

\begin{tabular}{lcc}
\multicolumn{3}{l}{ Collinearity Statistics } \\
\hline & VIF & Tolerance \\
\hline income & 1.33 & 0.752 \\
control & 1.33 & 0.752 \\
\hline & & {$[3]$}
\end{tabular}

Figure 23. Linear Regression Output

As can be seen from the output, the Durbin-Watson statistic, VIF, and Tolerance values along with the coefficients of the variables in the model are calculated. Additionally, if the F Test is selected in the Model Fit section, the meaningfulness of the model as a whole is tested.

\subsubsection{Exploratory Factor Analysis}

In order to reveal the findings of the construct validity of a measurement tool, EFA is used when there is no strong a priori regarding the components of the structure intended to measure (Henson \& Roberts, 2006). PCA is also used for similar purposes to EFA when there is no strong a priori regarding the structure and it is thought to be equivalent to EFA; however, the mathematics it uses makes simple mathematical groupings instead of revealing the latent variable in behavioural sciences, and therefore, it is thought to give biased results (Fokkema \& Grieff, 2017). The screen of an EFA in practice is presented in Figure 24. 


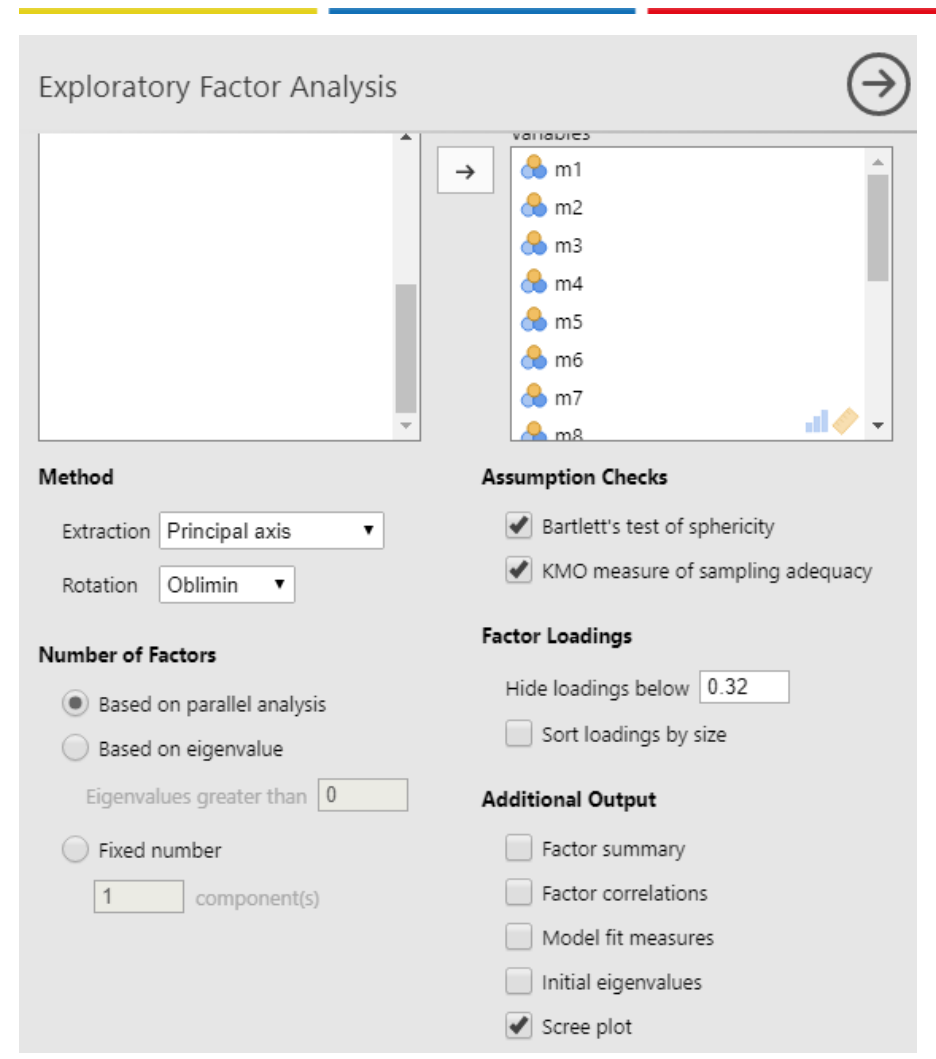

Figure 24. Exploratory Factor Analysis Menu

Firstly, all of the items required to be within the scope of the analysis are entered into the box on the right. From the Method heading in the menu, the Extraction section is used to select Exploratory Factor Analysis. The Rotation section right beneath contains the oblique or orthogonal rotation methods to be used in creating the factor structure. The Number of Factors section refers to the method to be used in determining the number of factors and contains the options for Eigenvalue or Parallel Analysis (Horn, 1965). Also in this section, the option to limit the number of dimensions based on an a priori is presented. On the top right of the menu, in the section regarding the testing of the assumptions of the analysis, the options for Bartlett's test and $K M O$ which is an analysis regarding the factorizability of items are selectable. In the Factor Loadings section right beneath lies a section in which the lowest factor load to be reported can be determined. In the Additional Output section of the analysis, options such as Scree plot, and Model fit measures to obtain fit indices similar to interdimensional correlation or structural equation modeling applications are presented. An output exemplifiying this practice is shown in Figure 25. 


\section{Exploratory Factor Analysis}

\begin{tabular}{|c|c|c|c|c|c|}
\hline & \multicolumn{4}{|c|}{ Factor } & \multirow[b]{2}{*}{ Uniqueness } \\
\hline & 1 & 2 & 3 & 4 & \\
\hline m1 & & & 0.532 & & 0.491 \\
\hline $\mathrm{m} 2$ & & & 0.645 & & 0.625 \\
\hline $\mathrm{m} 3$ & & & 0.501 & & 0.503 \\
\hline $\mathrm{m} 4$ & & & 0.613 & & 0.451 \\
\hline $\mathrm{m} 5$ & & & 0.476 & & 0.756 \\
\hline $\mathrm{m} 6$ & & 0.458 & & 0.327 & 0.456 \\
\hline $\mathrm{m} 7$ & & & & 0.495 & 0.741 \\
\hline $\mathrm{m} 8$ & & & & 0.373 & 0.452 \\
\hline $\mathrm{m} 9$ & & & & 0.534 & 0.699 \\
\hline $\mathrm{m} 10$ & & 0.808 & & & 0.335 \\
\hline $\mathrm{m} 11$ & & 0.751 & & & 0.464 \\
\hline $\mathrm{m} 12$ & & 0.579 & & & 0.640 \\
\hline $\mathrm{m} 13$ & 0.376 & & & & 0.467 \\
\hline $\mathrm{m} 14$ & 0.745 & & & & 0.334 \\
\hline $\mathrm{m} 15$ & 0.805 & & & & 0.384 \\
\hline $\mathrm{m} 16$ & 0.765 & & & & 0.394 \\
\hline $\mathrm{m} 17$ & 0.660 & & & & 0.460 \\
\hline
\end{tabular}

Note. 'Principal axis factoring' extraction method was used in combination with a 'oblimin' rotation
Assumption Checks

\begin{tabular}{ccc}
\hline \multicolumn{3}{l}{ Bartlett's Test of Sphericity } \\
\hline$\chi^{2}$ & df & $p$ \\
\hline 2632 & 136 & $<.001$ \\
\hline
\end{tabular}

KMO Measure of Sampling Adequacy

\begin{tabular}{lc}
\hline & MSA \\
\hline Overall & 0.903 \\
$\mathrm{~m} 1$ & 0.896 \\
$\mathrm{~m} 2$ & 0.865 \\
$\mathrm{~m} 3$ & 0.948 \\
$\mathrm{~m} 4$ & 0.912 \\
$\mathrm{~m} 5$ & 0.804 \\
$\mathrm{~m} 6$ & 0.912 \\
$\mathrm{~m} 7$ & 0.882 \\
$\mathrm{~m} 8$ & 0.925 \\
$\mathrm{~m} 9$ & 0.858 \\
$\mathrm{~m} 10$ & 0.892 \\
$\mathrm{~m} 11$ & 0.875 \\
$\mathrm{~m} 12$ & 0.937 \\
$\mathrm{~m} 13$ & 0.933 \\
$\mathrm{~m} 14$ & 0.893 \\
$\mathrm{~m} 15$ & 0.894 \\
$\mathrm{~m} 16$ & 0.882 \\
$\mathrm{~m} 17$ & 0.913 \\
\hline
\end{tabular}

[3]

Eigenvalues

Scree Plot

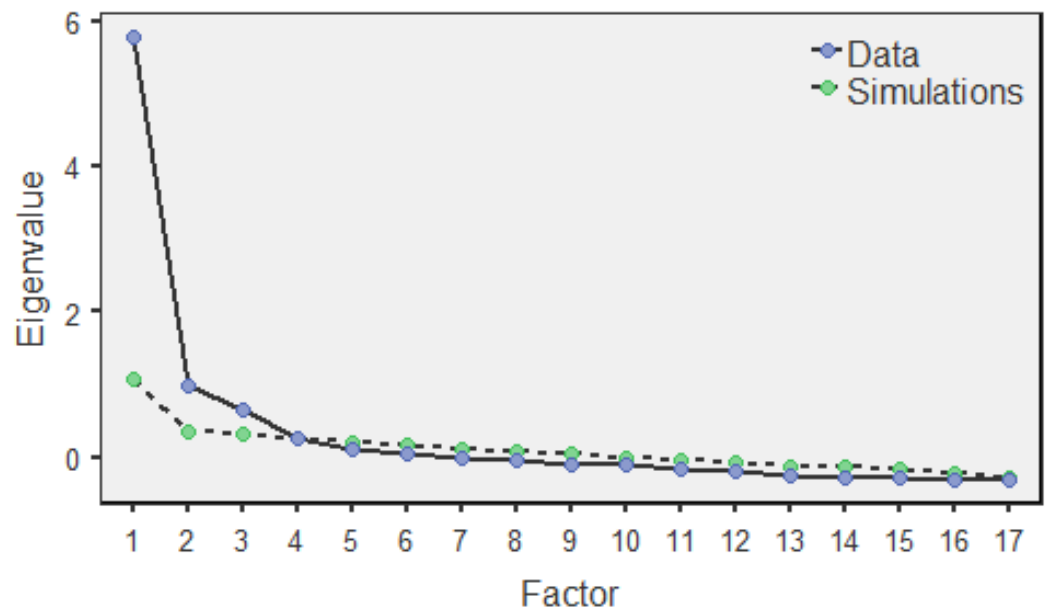

Figure 25. Exploratory Factor Analysis Output

\subsubsection{Confirmatory Factor Analysis}

CFA is used to determine whether or not the predicted structure is present in the dataset at hand in cases where a strong a priori regarding the structure is apparent to the researcher (Brown, 2015). Therefore, it may be stated that CFA is used when a new or previously developed scale for a structure with theoretically sound dimensions is to be used on a different sample or adapted to a different culture. An example for a 5-item single dimension scale in a CFA application is presented in Figure 26. 


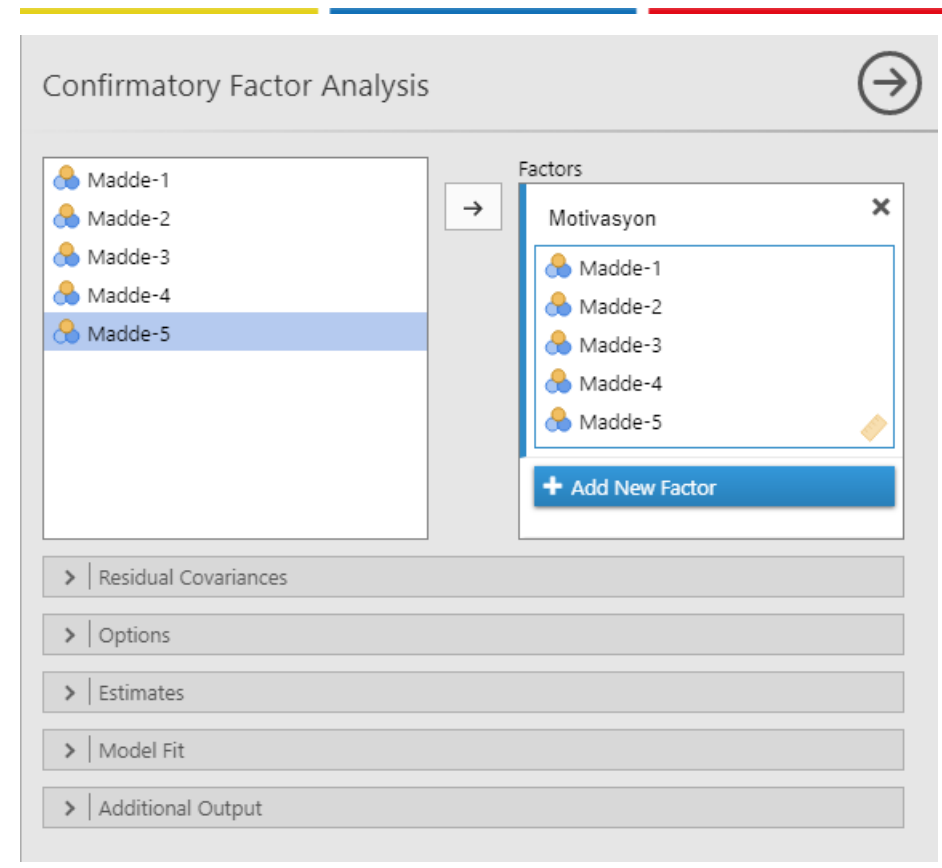

Figure 26. Confirmatory Factor Analysis Menu

In the top of the screen seen in Figure 26, the section in which the dimensions for the items to be analyzed are defined can be seen. Here, the latent variable is given a name and the items related to it are moved to the box below it. If there is more than one dimension in the scale, the "Add new factor" command is clicked and in the new box that opens, the same process for the first latent variable is repeated for the new factor.

The Residual Covariances tab is used to define the covariance between the residual variances of the observed variable to improve the model-data fit when necessary. However, to conduct this operation, the Modification indices command under the Additional Output tab at the bottom must be selected to obtain the suggested modifications. Under the Options heading, the functions regarding how to deal with missing values are present under Missing Values Method while the latent variable scale assignment which needs to be performed before analysis in structural equation modeling techniques can be done through the Constraints function. In the Estimates tab lie the Results and Statistics sections. The $\mathrm{z}$ and $\mathrm{p}$ values and confidence intervals for the estimated factor loads may be requested from here. In the Model Fit tab, the reported fit indices regarding the model-data fit in structural equation modeling are presented. While the values for $\chi^{2}$, CFI, TLI, and RMSEA are provided as default, the values for SRMR, AIC, and BIC may also be selected. Lastly, the path diagram for the visualization of the model may be requested from the Additional Output tab mentioned previously on the subject of modification indices. The output obtained for this model is presented in Figure 27. 
Confirmatory Factor Analysis

\begin{tabular}{cccccc}
\multicolumn{7}{l}{ Factor Loadings } & \multicolumn{1}{c}{} \\
\hline Factor & Indicator & Estimate & SE & Z & P \\
\hline Motivasyon & Madde-1 & 0.973 & 0.0513 & 18.98 & $<.001$ \\
& Madde-2 & 0.954 & 0.0472 & 20.22 & $<.001$ \\
& Madde-3 & 0.939 & 0.0456 & 20.60 & $<.001$ \\
& Madde-4 & 0.949 & 0.0455 & 20.84 & $<.001$ \\
& Madde-5 & 0.214 & 0.0501 & 4.28 & $<.001$ \\
\hline
\end{tabular}

[3]

Model Fit

\begin{tabular}{ccc}
\multicolumn{3}{l}{ Test for Exact Fit } \\
\hline$\chi^{2}$ & df & $p$ \\
\hline 17.5 & 5 & 0.004 \\
\hline
\end{tabular}

\begin{tabular}{ccccc}
\multicolumn{2}{l}{ Fit Measures } & & & \\
\hline & & & \multicolumn{2}{c}{ RMSEA $90 \% \mathrm{Cl}$} \\
\cline { 4 - 5 } CFI & TLI & RMSEA & Lower & Upper \\
\hline 0.988 & 0.977 & 0.0805 & 0.0416 & 0.123 \\
\hline
\end{tabular}

Figure 27. Confirmatory Factor Analysis Output

\subsubsection{Reliability}

Reliability, in a broad sense, refers to the degree to which the measurement tool is free of random faults (Baykul, 2000). While reliability also has other definitions and meanings, its most frequent use is through the Cronbach Alpha $(\alpha)$ coefficient as an indicator of internal consistency due to its applicability and interpretability (Padilla \& Divers, 2016). In addition to Cronbach's $\alpha$, Jamovi also allows for the reporting of McDonald's Omega $(\omega)$ coefficient, which has lately been included in recent research as "composite reliability", as an indicator of reliability in the sense of internal consistency.

The Reliability tab under the Factor option in Jamovi results in the screen shown in Figure 28.

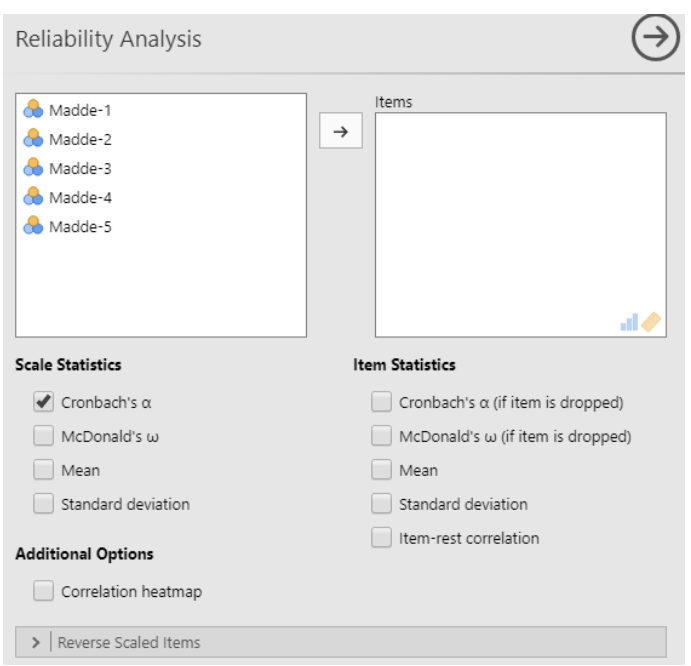

Figure 28. Reliability Analysis Screen 
On the screen portrayed in Figure 28, first the items to be used in the analysis are selected and moved to the box on the right. In the Scale Statistics section, the options to request Cronbach's $\alpha$ and McDonald's $\omega$ coefficients along with the arithmetic mean and standard deviation of the scale are presented. Under the Item Statistics section are values regarding items. Here, the change in the reliability coefficient, arithmetic means of the items, and standard deviation in the event that any one item is removed from the scale along with the correlation of each individual item with the test as a whole may be requested. In the Additional Options section, the correlation of items with each other is presented with a heat map. The Reverse Scaled Items tab at the bottom aids in determining items with inverted meanings to speed up processes. The outputs of Reliability analyses are shown in Figure 29.

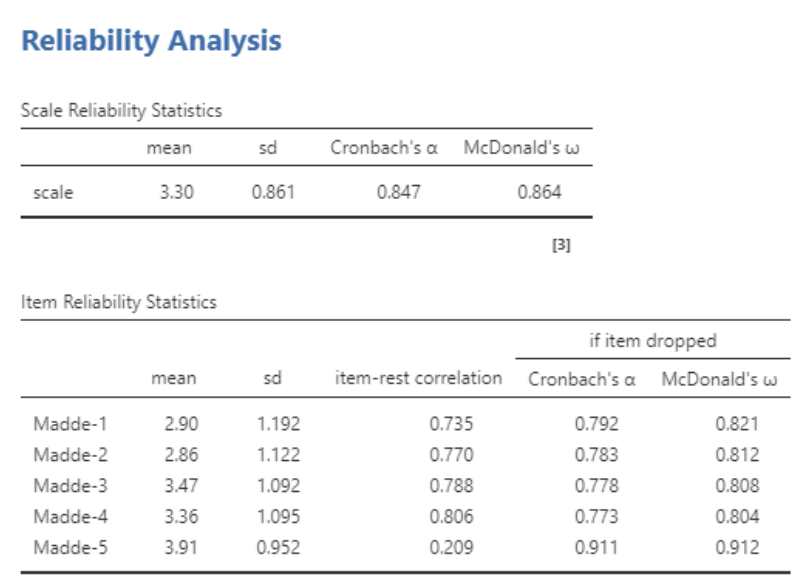

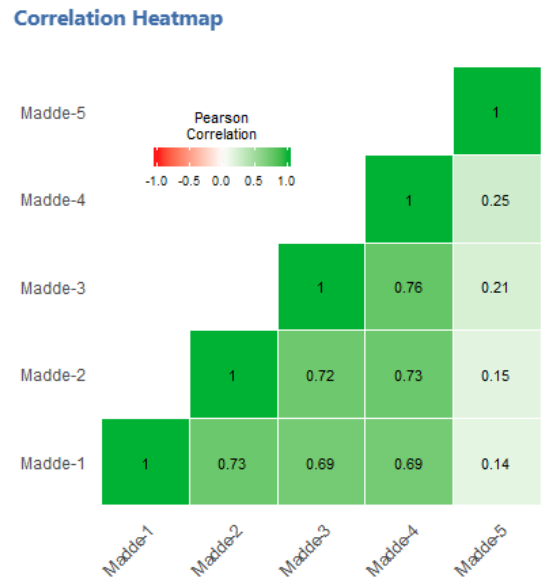

Figure 29. Reliability Analysis Output

\subsection{Extending Features through Modules}

Beyond the basic analyses Jamovi provides, other analyses may be conducted through modules. The Modules button can be used to see, review, and load modules developed for Jamovi (Figure 30).

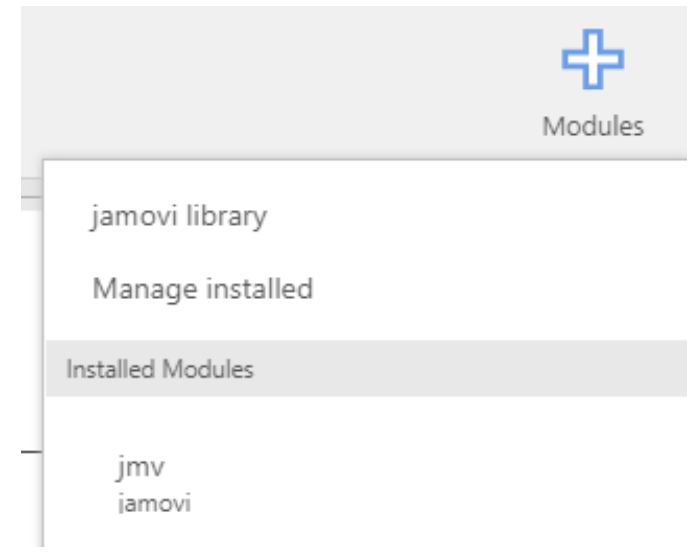

Figure 30. Modules Menu

By following the Modules and Jamovi library path, all of the modules that can be loaded can be listed as shown in Figure 31.

As of the date this article was written, the Jamovi module library was home to many modules such as, $R j$ which allows R code to be run in Jamovi, jpower which allows for Power analysis, $G A M L j$ for linear models, $j s q$ for Bayesian methods, and MAJOR for meta-analysis. Jamovi modules continue to expand with the contributions of developers. 


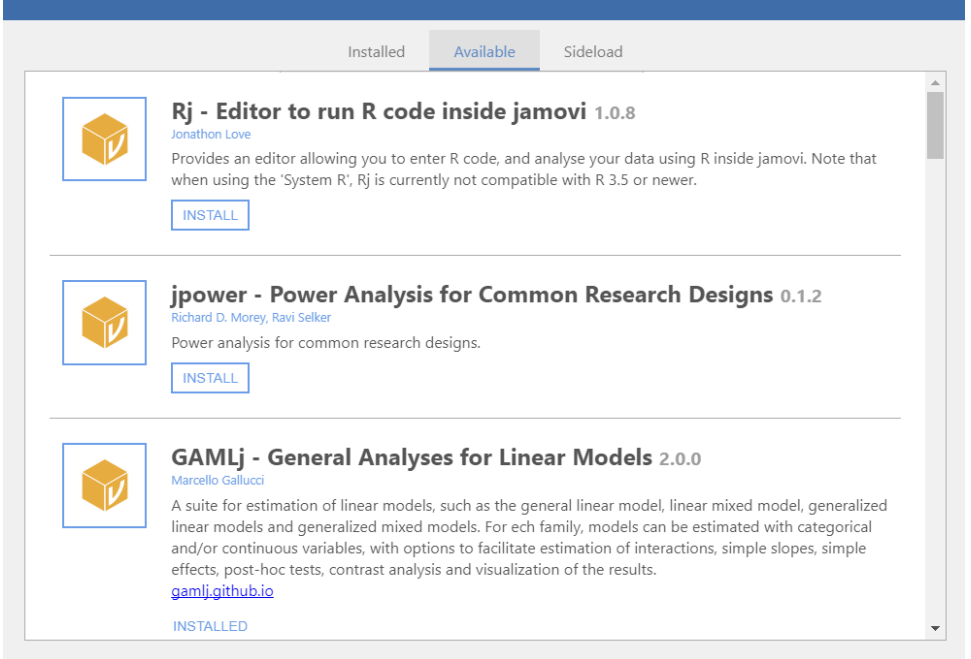

Figure 31. Jamovi Modules

\subsection{Options}

Jamovi has certain basic options regarding theming and number portrayal. Clicking on the three dots on the top right corner provides access to these settings. The settings menu that appears is shown in Figure 32.

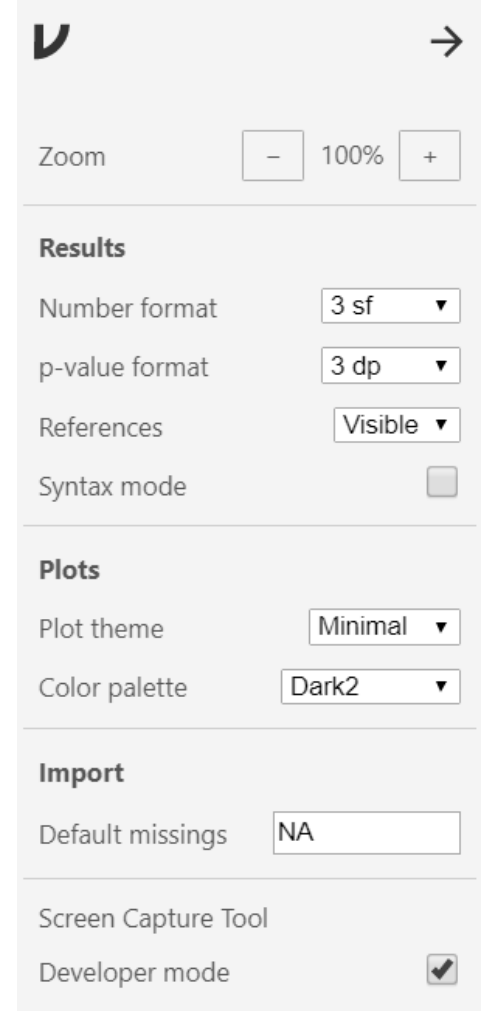

Figure 32. Jamovi Options

From this menu, basic options such as number and $\mathrm{p}$ value format, showing or hiding references, and graphics themes can be set. 


\section{AVAILABILITY}

To download Jamovi, visit https://www.jamovi.org, and to access the source code of the jamovi project visit the github page at https://github.com/jamovi/. Additionally, a detailed explanation of Jamovi prepared by Navarro and Foxcroft (2019) is available as a free e-book from https://www.learnstatswithjamovi.com/.

\section{Conflicts of Interest}

The authors declare no conflict of interest.

\section{ORCID}

Murat Doğan Şahin (iD https://orcid.org/0000-0002-2174-8443

Eren Can Aybek (D) https://orcid.org/0000-0003-3040-2337

\section{REFERENCES}

Amazon (2019). Search Results. https://www.amazon.com/s?k=statistics+for+social+science Accessed on 20 September 2019.

Baykul, Y. (2000). Ĕgitimde ve psikolojide ölçme [Measurement and Evaluation in Education]. Ankara: ÖSYM Yayınları.

Brown, T.A. (2015). Confirmatory factor analysis for applied research. New York: The Guilford Press.

Field, A. (2013). Discovering statistics using IBM SPSS statistics. London: SAGE Pub.

Fokkema, M. \& Grieff, S. (2017). How performing PCA and CFA on the same data equals trouble. European Journal of Psychological Assessment, 33(6), 399-402.

GNU (2019). What is GNU? https://www.gnu.org/ Accessed on 28 September 2019.

Horn, J. L. (1965). A rationale and test for the number of factors in factor analysis. Psychometrika, 30(2), 179-85.

Henson, H. K. \& Roberts, J. K. (2006). Use of exploratory factor analysis in published research: Common errors and some comment on improved practice. Educational and Psychological Measurement, 66(3). 393-416.

JASP Team (2019). JASP (Version 0.11.1) [Computer software].

Kline, R. B. (2009). Becoming a behavioral science researcher: A guide to producing research that matters. New York: Guilford Press.

Muenchen, R.A. (2019). The Popularity of Data Science Software. http://r4stats.com/articles/popularity/. Accessed on 20 September 2019.

Navarro, D.J. \& Foxcroft, D.R. (2019). Learning statistics with jamovi: A tutorial for psychology students and other beginners. (Version 0.70). doi: 10.24384/hgc3-7p15 [Available from http://learnstatswithjamovi.com]

Padilla, M. A \& Divers, J. (2016). A Comparison of composite reliability estimators: Coefficient omega confidence intervals in the current literature. Educational and Psychological Measurement, 76(3) 436-453

$\mathrm{R}$ Core Team (2019a). What is R. https://www.r-project.org/about.html Accessed on 25 September 2019.

R Core Team (2019b). Contributed Packages. https://cloud.r-project.org/web/packages Accessed on 01 October 2019.

RKWard (2019). About RKWard. https://rkward.kde.org/About.html Accessed on 05 October 2019.

RStudio (2019). RStudio. https://rstudio.com/products/rstudio/ Accessed on 05 October 2019. The jamovi project (2019a). Jamovi (Version 1.0) [Computer Software].

The jamovi project (2019b). About. https://www.jamovi.org/about.html Accessed on 06 October 2019.

Warner, R.M. (2008). Applied statistics: From bivariate through multivariate techniques. USA: SAGE Pub. 